\title{
Evaluasi Stimulasi Hydraulic Fracturing Menggunakan Software Mfrac
}

\author{
Novita Ratna Dila \\ ${ }^{1)}$ Program Studi Teknik Perminyakan, Fakultas Teknik, Universitas Proklamasi 45 \\ Corresponding author, email : novitaratnadila@gmail.com
}

\begin{abstract}
Abstrak
Perekahan hidraulik (hydraulic fracturing) merupakan suatu usaha untuk meningkatkan produktivitas suatu sumur dengan jalan membuat saluran konduktif bagi fluida produksi untuk mengalir dari reservoir menuju sumur. Keberhasilan dari pelaksanaan perekahan hidraulik ini dapat diketahui dari beberapa parameter. Adapun parameter keberhasilan tersebut diantaranya peningkatan permeabilitas formasi, peningkatan indeks produktivitas (PI) dan peningkatan laju produksi.Tujuan dari Perekahan hidraulik akan membahas evaluasi keberhasilan setelah perekahan hidraulik dilakukan, dimana yang menjadi acuan adalah kenaikan permeabilitas dan peningkatan laju produksi.Metodologi penelitian ini, menggunakan software MFrac Simulation dari Meyer \& Associates, Inc. yang dimiliki oleh service company. Dengan memasukkan data reservoir, data lithologi batuan, data komplesi sumur, data proppant, data fluida perekah serta data-data lain yang terkait. Adapun tahap-tahap dari operasi stimulasi hydraulic fracturing ini meliputi step rate test, minifrac, evaluasi minifrac, dan main fracturing. Peningkatan produktivitas sumur terlihat sangat jelas dari hasil perbandingan productivity index (PI) sebelum dan sesudah hydraulic fracturing. Hasil perhitungan memperlihatkan bahwa dari hasil software Mfrac menunjukkan nilai PI naik 2,8126 kali lebih besar daripada PI sebelum hydraulic fracturing.
\end{abstract}

Kata Kunci : Hydraulic Fracturing, MFrac Simulation, Propprant, Productivity Index.

\begin{abstract}
Hydraulic fracturing is an attempt to increase the productivity of a well by making a conductive channel for the production fluid to flow from the reservoir to the well. The success of the implementation of hydraulic fracturing can be seen from several parameters. The success parameters include increasing formation permeability, increasing productivity index (PI) and increasing production rates. The purpose of hydraulic fracturing will be to discuss the success of the evaluation after hydraulic fracturing is done, where the reference is to increase permeability and increase the rate of production.The methodology of this research, using MFrac Simulation software from Meyer \& Associates, Inc. owned by a service company. By entering reservoir data, lithological data of rocks, well completion data, proppant data, recycled fluid data and other related data. The stages of hydraulic fracturing stimulation operations include step rate test, minifrac, minifrac evaluation, and playing fracturing. Increased productivity of the well is very clear from the results of the comparison of productivity index (PI) before and after hydraulic fracturing. The calculation results show that from the Mfrac software results show the PI value increases 2.8126 times greater than the PI before hydraulic fracturing.
\end{abstract}

Keywords: Hydraulic Fracturing, MFrac Simulation, Propprant, Productivity Index.

\section{Pendahuluan}

Produksi minyak dan gas bumi merupakan kegiatan mengangkat minyak dan gas bumi dari sumur menuju ke permukaan. Metode produksi minyak dan gas bumi ada tiga yaitu primary recovery, secondary recovery dan tertiary recovery. Pada dasarnya, pelaksanaan kegiatan produksi akan diikuti oleh penurunan laju produksi. Salah satu penyebab turunnya laju produksi adalah adanya formation damage. Upaya peningkatan laju produksi dan penanganan formation damage dapat dilakukan dengan cara stimulasi. Stimulasi merupakan suatu pekerjaan merangsang sumur yang dilakukan karena adanya permasalahan pada formasi seperti scale, parafin, kepasiran dan lainnya sehingga terjadi penurunan produksi. Tujuan stimulasi adalah untuk memudahkan minyak dan gas bumi mengalir dari reservoir menuju sumur sehingga dapat meningkatkan kapasitas produksi dan jumlah perolehan hidrokarbon. Metode stimulasi pada dasarnya dibedakan menjadi dua yaitu acidizing dan hydraulic fracturing. Adapun metode stimulasi yang akan dibahas pada paper ini adalah hydraulic fracturing.

Perekahan hidraulik (hydraulic fracturing) merupakan suatu usaha untuk meningkatkan produktivitas suatu sumur dengan jalan membuat saluran konduktif bagi fluida produksi untuk mengalir dari reservoir menuju sumur. Proses perekahan dilakukan dengan menginjeksikan fluida perekah pada laju dan tekanan injeksi tinggi yang melebihi tekanan rekah formasinya. Fluida yang diinjeksikan harus mempunyai harga viskositas tertentu, sehingga dapat membawa proppant dengan baik hingga ke ujung rekahan dengan leakoff yang kecil. Laju injeksi yang konstan harus 
dipertahankan setelah perekahan dan bersamaan dengan itu proppant diinjeksikan ke dalam formasi untuk menahan rekahan yang telah terbentuk. Pemompaan akan dihentikan apabila seluruh proppant yang direncanakan berada dalam formasi dan mengisi semua bagian rekahan. Material pengganjal yang berada di dalam rekahan akan mempunyai permeabilitas yang lebih baik daripada permeabilitas formasi sebelumya. Perekahan hidraulik pada paper ini akan membahas evaluasi keberhasilan setelah perekahan hidraulik dilakukan, dimana yang menjadi acuan adalah kenaikan permeabilitas dan peningkatan laju produksi.

Keberhasilan dari pelaksanaan perekahan hidraulik ini dapat diketahui dari beberapa parameter. Adapun parameter keberhasilan tersebut diantaranya peningkatan permeabilitas formasi, peningkatan indeks produktivitas (PI) dan peningkatan laju produksi.

Meyer merupakan software berbasis windows yang dikeluarkan oleh salah satu perusahaan yaitu Meyer associated, Inc dan digunakan oleh salah satu services company, software ini digunakan untuk mendesain dan mengevaluasi suatu proses hydraulic fracturing. Software Meyer terdiri dari tujuh bagian utama, yaitu:

1. MFrac, terdiri dari option, data input, run or performing calculation, plots graphical presentastion, generating reports dan program data base.

2. MView, terdiri dari parameters, data, real time menu, simulation set up dan plots.

3. MinFrac, terdiri dari options, data input, analysis dan output.

4. MProd, terdiri dari data input, run or performing calculations dan plots.

5. MNpv, terdiri dari options, data input, economic data, run, plots dan graphical presentations.

6. MFast, terdiri dari data dan output

7. MPwri, terdiri dari options, data input, run or performing calculations, plot dan graphical presentation

\section{Metodologi}

Proses evaluasi pelaksanaan hydraulic fracturing terinci dalam bagan alir pada Gambar 1.

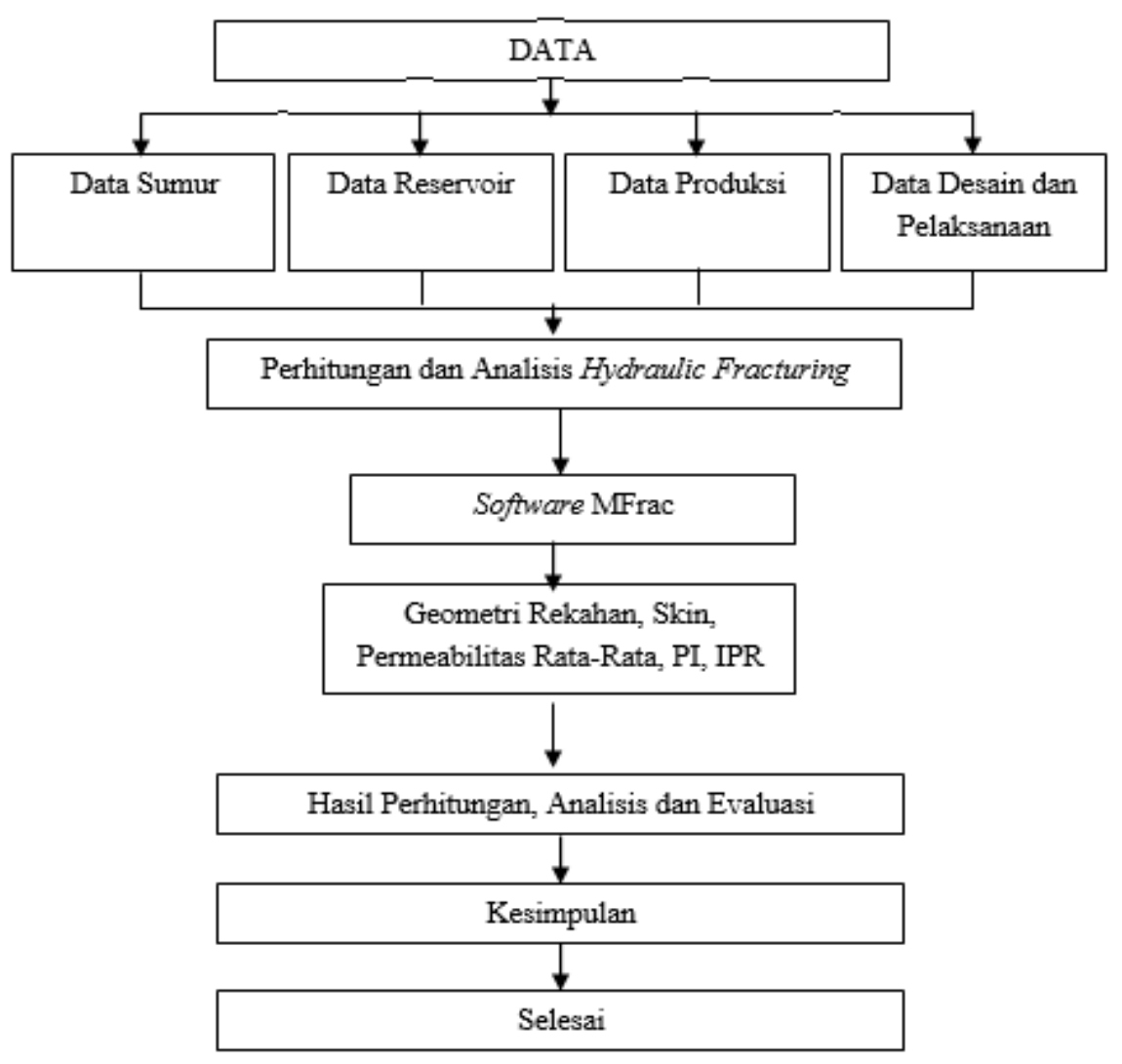

Gambar 1. Diagram Alir Penelitian 


\section{Hasil dan Pembahasan}

Desain pekerjaan hydraulic fracturing meliputi fluida perekah, proppant, geometri rekahan, volume total fluida injeksi, laju pompa, dan Sebagainya. Pemilihan fluida perekah biasanya didasarkan pada data reservoir dan lithologi batuan, dimana fluida perekah yang akan dipakai dalam pelaksanaan hydraulic fracturing harus sesuai dengan formasi yang akan direkahkan. Fluida perekah yang digunakan dalam pekerjaan hydraulic fracturing pada sumur produksi adalah water-based fluid dengan tambahan beberapa additive. Untuk mendapatkan komposisi fluida perekah tersebut, dilakukan simulasi laboratorium dengan menggunakan semua bahan kimia yang akan digunakan di lapangan sehingga diperoleh data penting berupa n' base gel sebesar 0,447982 dan $\mathrm{k}^{\prime}$ base gel sebesar 0,031132 $\mathrm{lb} \cdot \mathrm{s}^{\mathrm{n}^{\prime}} / \mathrm{ft}^{2}$. Sedangkan untuk pemilihan proppant didasarkan pada ukuran, kualitas, kekuatan proppant dan bentuk butiran proppant, dimana proppant yang dipilih harus sesuai dengan komplesi dan cocok dengan formasi yang akan direkahkan. Untuk menghindari terjadinya bridging, atau pengendapan pada muka lubang perforasi, maka ukuran proppant harus sesuai dengan ukuran lubang perforasi. Proppant yang digunakan dalam pelaksanaan hydraulic fracturing pada sumur produksi adalah jenis carbo ceramics yang dikenal Carbolite 20/40. Jenis proppant ini memiliki ukuran average diameter 0,029 inch, porosity $35 \%$, dan specific gravity 2,72.

Pelaksanaan stimulasi hydraulic fracturing membutuhkan perencanaan yang tepat dan akurat terutama sebelum dilakukan main fracturing. Main fracturing mempunyai resiko kegagalan yang besar karena berlangsung dalam waktu singkat, tekanan tinggi dan jumlah proppant yang besar, sehingga diperlukan serangkaian studi simulasi untuk memperoleh gambaran desain hydraulic fracturing yang akan terjadi dengan pendekatan parameter reservoir dan konfigurasi sumur yang ada.

Pada sumur produksi, desain pekerjaan hydraulic fracturing dibuat secara komputerisasi dengan menggunakan software MFrac Simulation dari Meyer \& Associates, Inc. yang dimiliki oleh service company. Dengan memasukkan data reservoir, data lithologi batuan, data komplesi sumur, data proppant, data fluida perekah serta data-data lain yang terkait, maka kita bisa mendesain suatu pekerjaan hydraulic fracturing yang optimal pada suatu reservoir menggunakan simulator tersebut.

Simulasi yang direncanakan menggunakan volume total slurry sebanyak 13715 US gallon dengan proppant sebanyak 32000 lbs. Dari hasil Simulasi tersebut didapatkan panjang rekahan (xf) yang terbentuk sepanjang 99 meter, tinggi rekahan (Hf) 4,8 meter, lebar rekahan $\left(W_{f}\right)$ 0,17 inch dan permeabilitas rekahan (kf) sebesar 465 $\mathrm{mD}$. Setelah simulasi desain dan disetujui, maka pelaksanaan program hydraulic fracturing berlinjut ke tahap pengerjaan. Pada pelaksanaan di lapangan, terdapat beberapa rangkaian proses kerja sebelum dilakukannya main fracturing. Hal ini dilakukan untuk memperoleh data-data yang dibutuhkan sehingga pelaksanaan main fracturing nantinya akan berjalan sesuai dengan yang diharapkan. Adapun tahap-tahap dari operasi stimulasi hydraulic fracturing ini meliputi step rate test, minifrac, evaluasi minifrac, dan main fracturing.
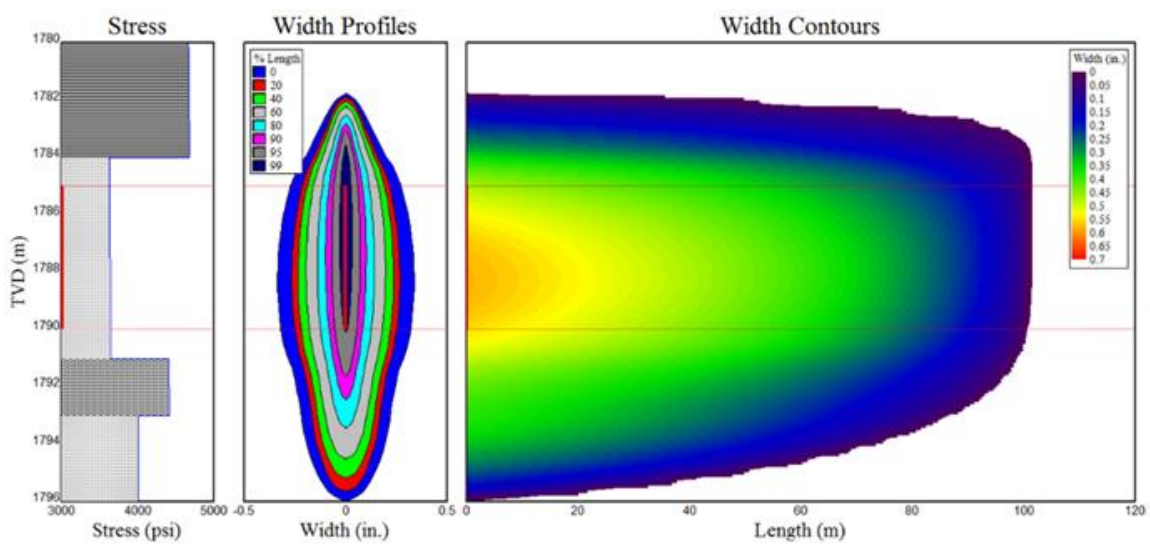

Gambar 2. Hasil Simulasi Initial Design Sumur Produksi 
Berdasarkan hasil pekerjaan yang optimum dari studi simulasi menggunakan software Mfrac yang terlihat pada Gambar 2, maka selanjutnya dilakukan eksekusi atau pelaksanaan di lapangan. Pada pelaksanaan di lapangan terdapat beberapa rangkaian proses kerja sebelum dilakukannya pekerjaan main fracturing. Hal ini dilakukan untuk memperoleh data-data yang dibutuhkan sehingga pelaksanaan main fracturing nantinya akan berjalan sesuai dengan yang diharapkan. Adapun rangkaian proses kerja sebelum dilakukannya main fracturing adalah pelaksanaan step rate test dan mini frac. Setelah dilakukan step rate test dan mini frac kemudian dilakukan design ulang yang merupakan final design berdasarkan data yang diperoleh dari step rate test dan mini frac.

Hasil simulasi geometri rekahan setelah redesign sumur produksi berdasarkan software Mfrac diperlihatkan oleh Gambar 3.

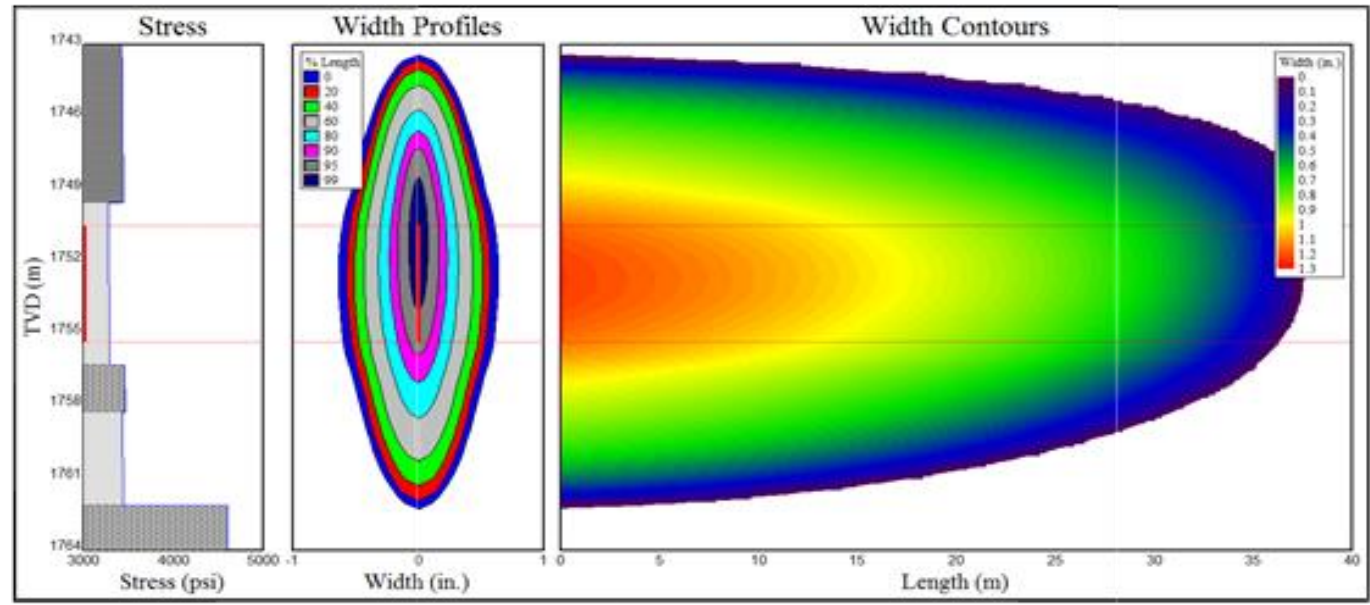

Gambar 3. Hasil Simulasi Final Design Sumur Produksi

Setelah final design dibuat, kemudian dilaksanakan pekerjaan main fracturing. Geometri rekahan yang terbentuk setelah pelaksanaan main

fracturing berdasarkan software MFrac dapat dilihat pada Gambar 4.

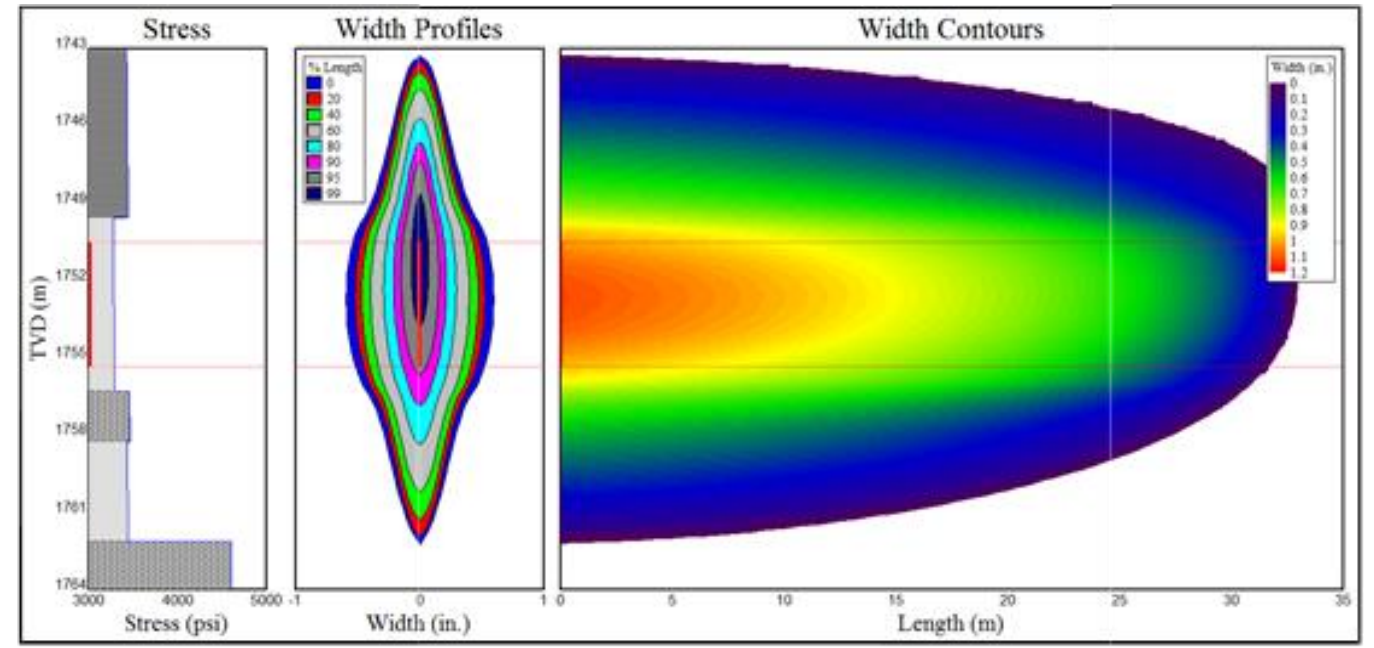

Gambar 4. Geometri Rekahan Aktual Sumur Produksi

Tabel 2 menunjukkan data geometri rekahan dan data penunjang lainnya pada saat design awal (initial design), desain akhir (final design) dan setelah pelaksanaan hydraulic fracturing (post job) berdasarkan software MFrac.Hasil evaluasi geometeri rekahan dan hasil evaluasi hyraulic fracturing dengan menggunakan software MFrac ditunjukkan pada tabel 1 dan tabel 2 Kenaikan performa produksi sumur produksi terlihat pada kurva IPR sebelum dan setelah pelaksanaan hydraulic fracturing sebagaimana ditunjukkan oleh Gambar 3 dan Gambar 4. 
Tabel 1. Hasil Evaluasi Geometri Rekahan Menggunakan Software MFrac

\begin{tabular}{|l|c|c|}
\hline \multicolumn{1}{|c|}{ Parameter } & Software & Satuan \\
\hline Panjang rekahan (Xf) & 104,992 & $\mathrm{Ft}$ \\
\hline Lebar rekahan rata-rata (Wf) & 0,26 & inch \\
\hline
\end{tabular}

Tabel 2. Hasil Evaluasi Hydraulic Fracturing Sumur Produksi

\begin{tabular}{|l|c|c|c|}
\hline \multirow{2}{*}{\multicolumn{1}{|c|}{ Parameter }} & \multicolumn{2}{c|}{ Sotfware } & \multirow{2}{*}{ Satuan } \\
\cline { 2 - 3 } & Sebelum & Sesudah & \\
\hline Faktor skin (s) & 12 & $-4,8990$ & - \\
\hline Permeabilitas (k) & 11,3 & 39,7486 & $\mathrm{mD}$ \\
\hline $\begin{array}{l}\text { Productivity Index } \\
\text { (PI) }\end{array}$ & 0,2482 & 0,6981 & STB/d/psi \\
\hline Kenaikan PI & - & 2,8126 & $\mathrm{kali}$ \\
\hline qt maksimum & 54,9998 & 129,8269 & $\mathrm{bfpd}$ \\
\hline
\end{tabular}

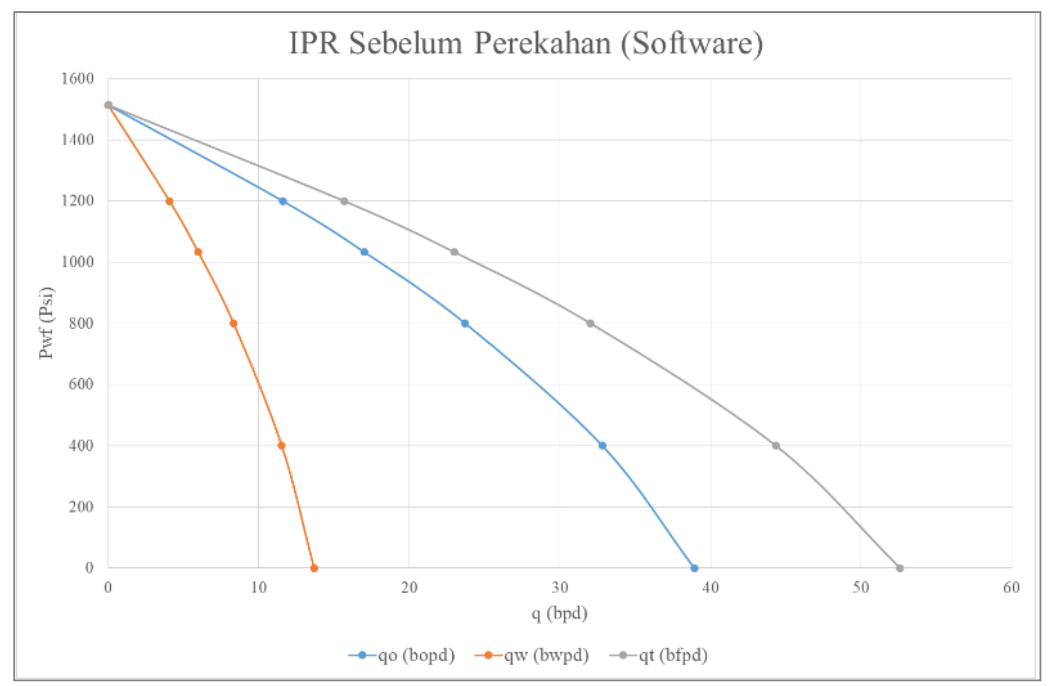

Gambar 4. Kurva IPR Sebelum Perekahan

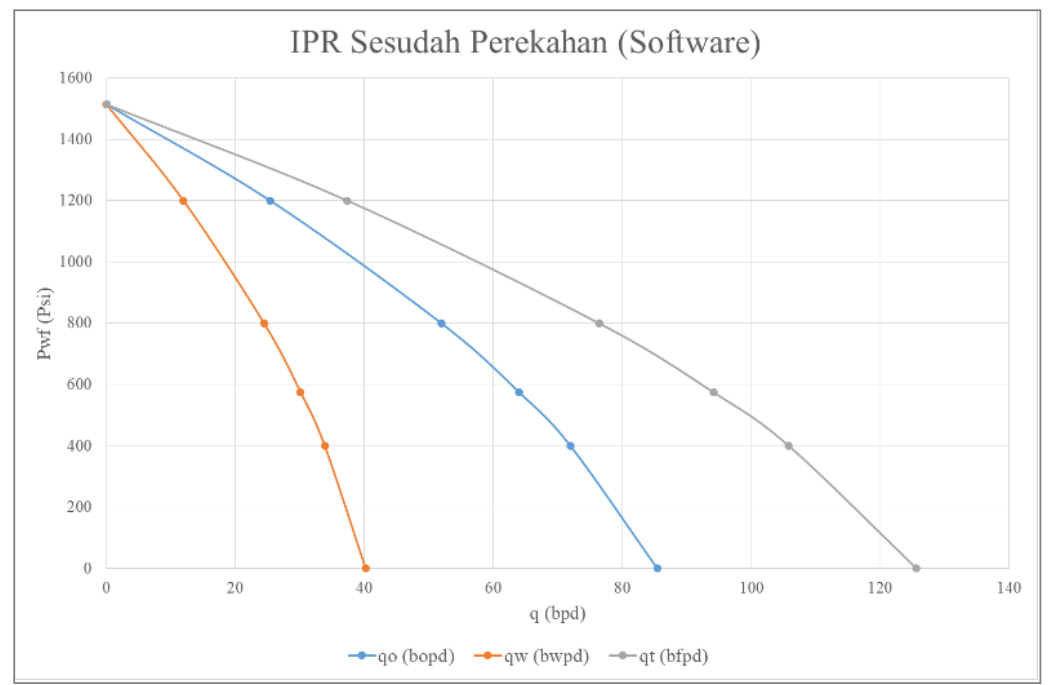

Gambar 5. Kurva IPR Sesudah Perekahan 
Hasil simulasi menggunakan software MFrac, menunjukkan nilai geometri rekahan aktual yang terbentuk setelah pelaksanaan hydraulic fracturing pada sumur produksi adalah dengan panjang rekahan 104,992 ft, dan lebar rekahan 0,26 inch.

Berdasarkan hasil geometri rekahan dari software MFrac diperoleh faktor skin (s) setelah hydraulic fracturing menunjukkan adanya perbaikan yaitu $-4,899$. Sedangkan berdasarkan hasil perhitungan manual, diperoleh faktor skin (s) setelah hydraulic fracturing juga menunjukkan adanya perbaikan yaitu -3,9618, yang menunjukkan adanya perbaikan dari faktor skin (s) sebelum hydraulic fracturing yaitu 12. Hasil perhitungan permeabilitas menunjukkan bahwa permeabilitas formasi telah naik setelah dilakukan hydraulic fracturing, yaitu dari permeabilitas formasi efektif $\left(\mathrm{k}_{\mathrm{ef}}\right) \quad 11,3 \mathrm{mD}$ menjadi permeabilitas formasi rata-rata (kavg) 39,7486 mD dengan menggunakan software MFrac

Peningkatan produktivitas sumur terlihat sangat jelas dari hasil perbandingan productivity index (PI) sebelum dan sesudah hydraulic fracturing. Hasil perhitungan memperlihatkan bahwa dari hasil software Mfrac menunjukkan nilai PI naik 2,8126 kali lebih besar daripada PI sebelum hydraulic fracturing.

Peningkatan produktivitas sumur juga terlihat sangat jelas dari kurva inflow performance relationship (IPR). Perhitungan untuk membuat kurva IPR ini menggunakan metode Pudjo Sukarno dengan aliran fluida tiga fasa. Kurva IPR tersebut menggambarkan perbedaan kemampuan berproduksi sumur produksi sebelum dan setelah hydraulic fracturing. Berdasarkan perhitungan, diketahui harga laju produksi total maksimum (qtmax) sebelum hydraulic fracturing sebesar 54,9998 BFPD. Berdasarkan perhitungan menggunakan software (qtmax) setelah pelaksanaan hydraulic fracturing meningkat menjadi 129,8269 BFPD.

\section{Kesimpulan}

1. Fluida perekah yang digunakan dalam pekerjaan hydraulic fracturing pada sumur produksi adalah water based fluid dengan tambahan beberapa additive dengan jenis proppant ini memiliki ukuran average diameter 0,029 inch, porosity $35 \%$, dan specific gravity 2,72 .
2. Geometri rekahan yang terbentuk dari simulasi menggunakan software MFrac memiliki panjang rekahan (Xf) sebesar 104,992 ft.

3. Faktor skin (S) setelah pelaksanaan hydraulic fracturing menunjukkan adanya perbaikan dari hasil perhitungan menggunakan software yaitu $-4,899$,

4. Permeabilitas formasi telah naik setelah dilakukan hydraulic fracturing, yaitu dari permeabilitas formasi efektif (k) $11,3 \mathrm{mD}$ menjadi permeabilitas formasi rata-rata ( $\mathrm{kavg}$ ) $39,7486 \mathrm{mD}$ dengan menggunakan software MFrac,

5. Hasil perhitungan software Mfrac menunjukkan nilai PI naik 2,8126 kali lebih besar daripada PI sebelum hydraulic fracturing.

6. Produksi sumur produksi menunjukkan adanya peningkatan laju produksi maksimum ( $\left.\mathrm{qt}_{\max }\right)$ dari sebelum hydraulic fracturing sebesar 54,9998 BFPD menjadi 129,8269 bfpd

7. Pelaksanaan hydraulic fracturing sumur produksi dinyatakan berhasil dengan tingkat keberhasilan sebesar 136,05\%.

\section{Daftar Pustaka}

Cahyono, M.S., 2013. Pengaruh Jenis Bahan pada Proses Pirolisis Sampah Organik menjadi Bio-Oil sebagai Sumber Energi Terbarukan. Jurnal Sains dan Teknologi Lingkungan Volume 5, Nomor 2, Juni 2013 Hal. 67-76.

Higman, C, And Van Der Berg, M. 2003. Gasification, Elsevier Science, USA.

Pranolo, H., 2010. Potensi Penerapan Teknologi Gasifikasi Tongkol Jagung Sebagai Sumber Energi Alternatif Di Pedesaan, Dalam Seminar Nasional Energi Terbarukan Indonesia di Universitas Jendral Sudirman Purwokerto.

Purwantana, B., An Nurisi, M., Markumning-sih, S., 2010. Kinerja Gasifikasi Limbah Padat Tebu (Saccharum Officinarum L.) Menggunakan Gasifier Unggun Tetap Tipe Downdraft.

Sudarsono, dkk., 2013. Pemanfaatan Limbah Serat Pati Organik sebagai Material Komposit Poliester. Laporan penelitian hibah bersaing Institut Sains \& Teknologi AKPRIND. 